\title{
Life history of an invasive freshwater shrimp Neocaridina davidi (Bouvier, 1904), (Decapoda: Caridea: Atyidae) in the Tomoe River, the Boso Peninsula, eastern Japan
}

Mitsukazu Mitsugi, Hiroshi Suzuki

\begin{abstract}
We studied the life history of Neocaridina davidi (Bouvier, 1904), native to mainland China and Korea, invading the Tomoe River, in the Boso Peninsula of eastern Japan. Sampling was carried out monthly from November 2012 to October 2013. Recruitment occurred from July to September, and the spawning season was from April to September. Large males with a carapace length more than $6.0 \mathrm{~mm}$ were rarely collected or absent from July to August, and, similarly, large females with a carapace length more than $7.0 \mathrm{~mm}$ were rarely collected or absent from September to October. Evidence from the current study suggests life span for this species is approximately 10-15 months. The life history of $N$. davidi is very similar to that of a congeneric species, $N$. denticulata, reported in previous studies.
\end{abstract}

Key words: Atydae, invasive species, life history, Boso Peninsula

\section{Introduction}

Neocaridina shrimp are commonly used as fishing bait or kept in aquaria as pets, and, as a result, have spread into various localities around the world (Englund \& Cai, 1999; Niwa, 2010; Klotz et al., 2013). Neocaridina davidi (Bouvier, 1904) is a landlocked species native to mainland China and the Korean peninsula (Liang, 2004). Klotz et al. (2013) claimed that Neocaridina heteropoda heteropoda Liang, 2002 and Neocaridina denticulata sinensis (Kemp, 1913) are junior synonyms of $N$. davi$d i$. Englund \& Cai (1999) reported that $N . d a-$ vidi (as $N$. denticulata sinensis) inhabited Oahu in Hawaii. Klotz et al. (2013) also reported that $N$. davidi was found in the Gillbach River in western Germany. Fujita et al. (2011) reported that $N$. davidi (as $N$. denticulata sinensis) inhabited three rivers in western Japan; the Gono River in Shimane Prefecture, the Saba River in Yamaguchi Prefecture, and the Kako River in Hyogo Prefecture. In these three rivers, $N$. $d a$ - vidi and N. denticulata (De Haan, 1844) co-inhabited locally (Fujita et al., 2011). On the other hand, it should be noted that $N$. denticulata is naturally distributed in areas of western Japan, mainland China, Taiwan, and the Korean peninsula (Kubo, 1938; Kamita, 1970; Suzuki \& Sato, 1994; Cai, 1996; Hamano et al., 2000; Liang, 2004; Hayashi, 2007; Suzuki \& Naruse, 2011; Toyota \& Seki, 2014).

We surveyed 281 sites of 27 rivers in the Boso Peninsula to investigate the freshwater shrimp fauna. Among these sites, we preliminarily surveyed 7 sites in the Tomoe River on July 30, 2012 (Sites 1 to 7 in Fig. 1) and collected Neocaridina species at 4 sites. We collected 1 specimen from Site 1, 5 specimens from Site 2, 40 specimens from Site 3, and 11 specimens from Site 4. Mitsugi et al. (2017) compared the morphological characteristics and mitochondrial DNA sequence variation of the specimens they have collected in 2013 and 2014 at the Site 3 of the Tomoe River with those of other Neocaridina species and con- 
cluded that the specimens from the Tomoe River were $N$. davidi. The time of invasion and invasion route of $N$. davidi to the Tomoe River are unknown. However, since the ornamental carp fish (Nishiki-goi) Cyprinus carpio (Linne, 1758 ) is frequently observed in the Tomoe river, $N$. davidi may have invaded the Tomoe River through intentional disposal or accidental escape from aquaria (Mitsugi et al., 2017).

The life history of $N$. davidi has not been studied previously either in its natural distribution areas or in the invasion areas. In contrast, the life history of $N$. denticulata was investigated by several studies, with some studies reporting that the life span of this species was 11-16 months (Ogawa et al., 1987; Sato et al., 1994; Oh et al., 2003). Niwa and Hamano (1990) recognized two life history groups from the same study area. One is a group with a life span of approximately 12 months, and another has a life span of approximately 2 months.
Neocaridina denticulata does not have a natural distribution in eastern Japan, and is not found in the Tomoe River (Kamita, 1970; Suzuki \& Sato, 1994; Hamano et al., 2000; Hayashi, 2007; Suzuki \& Naruse, 2011; Toyota $\&$ Seki, 2014). In the present study, we investigated the life history of $N$. davidi in Site 3 of the Tomoe River where many specimens were collected in the preliminary survey on July 30 , 2012. And we compare the life history of the Tomoe River population of $N$. davidi with that of $N$. denticulata reported in other areas in the previous studies, with the purpose of examining the differences in life history between the two species.

\section{Materials and Methods}

\section{Study site}

The Tomoe River is $9.2 \mathrm{~km}$ in length and flows through the Boso Peninsula to the Pacific

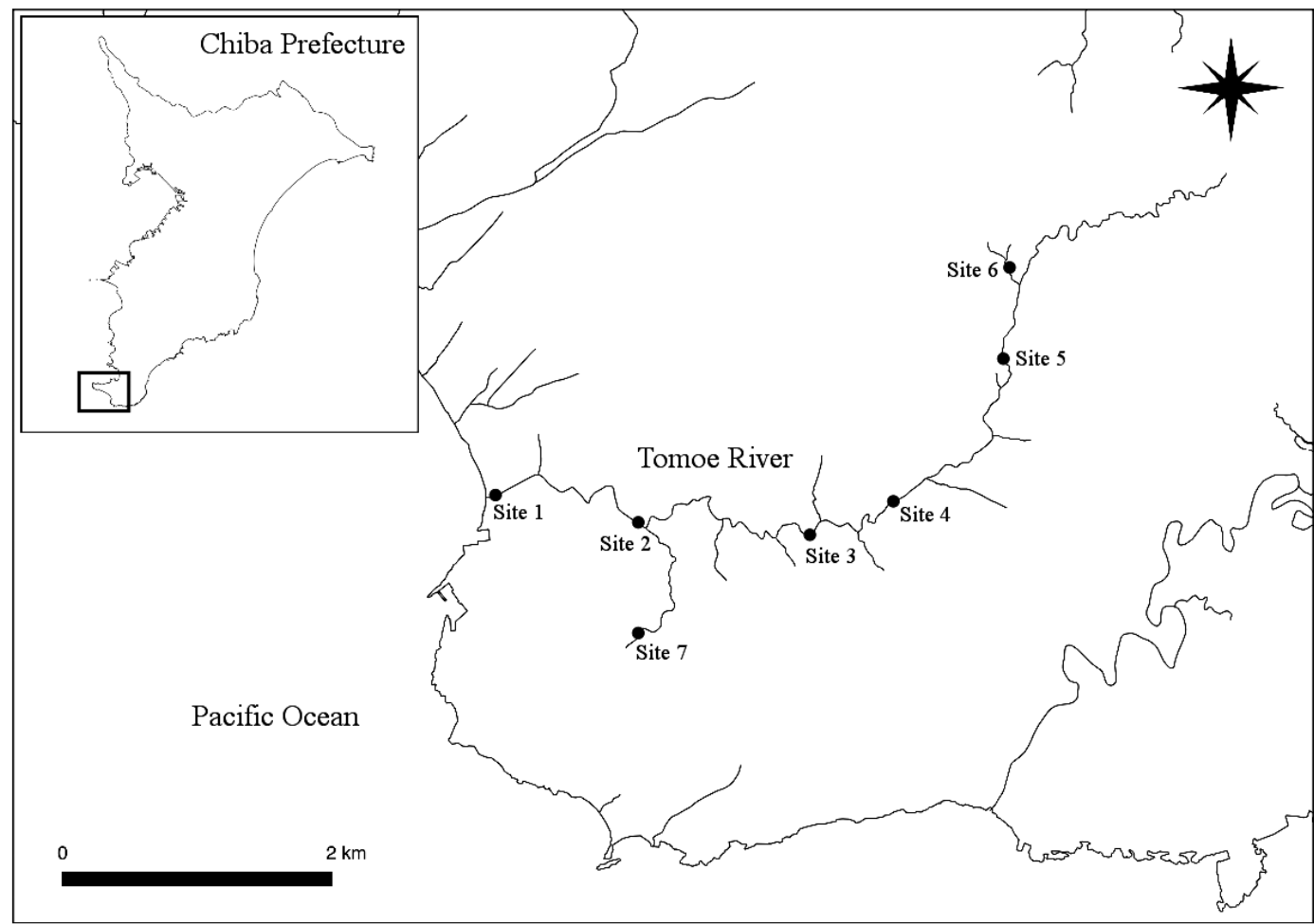

Fig. 1. Map of the Tomoe River and the location of the study sites. 
Ocean. The study area is located at a distance of $3.2 \mathrm{~km}$ from the estuary, at an altitude of $15 \mathrm{~m}$ (Site 3 in Fig. 1), and with a river width at the study area of approximately $3 \mathrm{~m}$. The bottom sediment was composed of sand and gravel. At the study site, $N$. davidi inhabited a shallow area (water depth of approximately $20 \mathrm{~cm}$ ) where the emergent plant Typha latifolia (Linne, 1753) was abundant.

\section{Sampling methods}

Sampling was carried out monthly from November 2012 to October 2013, using a hand net with a $25 \mathrm{~cm}$-wide mouth (mouth area of approximately $420 \mathrm{~cm}^{2}$ mouth area and mesh size of $1.0 \mathrm{~mm})$. All samplings were performed by the same person (MM) by sweeping the hand net through the water 15 times. The water temperature was measured by sinking the stick thermometer (Shinwa Rules, Sanjo, Japan; Item Code: 72508$)$ to the bottom of the water at each sampling. Collected specimens were fixed and preserved in $80 \%$ ethanol.

\section{Measurements and method of observation of specimens}

Neocaridina davidi is distinguished from other Neocaridina species by the following combination of characters; the rostrum reaches near to, or is slightly beyond, distal end of the third segment of the antennular peduncle, the propodus of the third pereiopod is more incurved in males than in females and the endopod of the first pleopod of the male is ovalshaped, and is 1.2-1.5 times as long as broad (Liang, 2004). The sex was determined by the shape of the endopod of the first pleopod (Cai, 1996; Englund \& Cai, 1999; Liang, 2004; Klotz et al., 2013; Toyota \& Seki, 2014), which was indistinguishable in specimens with a carapace length less than $3.0 \mathrm{~mm}$; hence, such specimens were defined as juveniles. Ovigerous condition in females was also recorded.

We measured the carapace length (from the postorbital margin to the posterior margin of the carapace) in all specimens. In addition, the maximum body length (from the postorbital margin to the end of the telson) was recorded for males and females. For measurements and observation, we used a stereomicroscope (M50, Leica Microsystems, Wetzlar, Germany) equipped with an eyepiece micrometer.

\section{Statistical analysis}

Size-frequency histograms were constructed using R 3.3.1 software (R Development Core Team, 2016), to analyze cohort structure, recruitment season, spawning period, and life span. First, in order to enable data analysis in R 3.3.1, data was tabulated every month for males, females and juveniles using the basic function "data.frame" implemented in R 3.3.1. Size-frequency histograms were then constructed with $0.5 \mathrm{~mm}$ carapace length size intervals using the generic function "hist" implemented in R 3.3.1.

\section{Results}

\section{Overview of collected specimens and water temperature}

A total of 1235 specimens were collected, including 319 juveniles, 463 males and 453 females (427 non-ovigerous females and 26 ovigerous females) (Table 1). The sex ratio (male : female) was $1: 0.98$. Carapace length of the collected specimens was in the range 0.8$7.7 \mathrm{~mm}$. The largest male was $6.4 \mathrm{~mm}$ (carapace length) and $25.5 \mathrm{~mm}$ (body length), collected in March 2013; while the largest female was $7.7 \mathrm{~mm}$ (carapace length) and $30.0 \mathrm{~mm}$ (body length), collected in May 2013. The highest water temperature recorded at the study site was $24.0^{\circ} \mathrm{C}$ in August 2013, while the lowest was $6.0^{\circ} \mathrm{C}$ in February 2013 (Fig. 2).

\section{Population fluctuation}

Size-frequency histograms for juveniles, males and females are shown in Fig. 3. In No- 
Table 1. Comparison of the life history of Neocaridina davidi in the Tomoe River and Neocaridina denticulata in previous studies.

\begin{tabular}{|c|c|c|c|c|c|}
\hline Reference & This study & Ogawa et al. (1987) & Niwa \& Hamano (1990) & Sato et al. (1994) & Oh et al. (2003) \\
\hline Species & Neocaridina davidi & Neocaridina denticulata & Neocaridina denticulata & Neocaridina denticulata* & Neocaridina denticulata* \\
\hline Locality & $\begin{array}{l}\text { Tomoe River, Chiba Pre- } \\
\text { fecture, Japan }\end{array}$ & $\begin{array}{l}\text { Ashida River, Hiroshima } \\
\text { Prefecture, Japan }\end{array}$ & $\begin{array}{l}\text { Sugou River, Hyogo Pre- } \\
\text { fecture, Japan }\end{array}$ & $\begin{array}{l}\text { Manose River, Kagoshima } \\
\text { Prefecture, Japan }\end{array}$ & Young-am, Korea \\
\hline Recruitment season & July-September & Early July, late September & Early June-early September & June-September & July-August \\
\hline Spawning period & April-September & Early May-early September & Early May-late September & Late April-early October & May-September \\
\hline $\begin{array}{l}\text { The period that large } \\
\text { shrimps were very } \\
\text { scarce collected or not } \\
\text { collected }\end{array}$ & July-October & August & June-August & June-September & October \\
\hline Life span & $10-15$ months (?) & 11,14 months & 2, 12 months & 12 months & $15.6-16.8$ months \\
\hline $\begin{array}{l}\text { Maximum size of } \\
\text { specimens }\end{array}$ & $\begin{array}{l}\text { Male: } 6.4 \mathrm{~mm}^{* *} \\
\quad\left(25.5 \mathrm{~mm}^{* * *}\right) \\
\text { Female: } 7.7 \mathrm{~mm}^{* *} \\
\quad\left(30.0 \mathrm{~mm}^{* * *}\right)\end{array}$ & $\begin{array}{l}\text { Male: } 24.3 \mathrm{~mm}^{* * *} \\
\text { Female: } 29.9 \mathrm{~mm}^{* * *}\end{array}$ & $\begin{array}{l}\text { Male: } 24.1 \mathrm{~mm}^{* * *} \\
\text { Female: } 28.6 \mathrm{~mm}^{* * *}\end{array}$ & $\begin{array}{l}\text { Male: } 27.1 \mathrm{~mm}^{* * *} \\
\text { Female: } 29.0 \mathrm{~mm}^{* * *}\end{array}$ & $\begin{array}{l}\text { Male: } 7.0-7.5 \mathrm{~mm}^{* *} \\
\text { Female : } 9.38 \mathrm{~mm}^{* *}\end{array}$ \\
\hline $\begin{array}{l}\text { Minimum size of } \\
\text { ovigerous females }\end{array}$ & $5.0 \mathrm{~mm}^{* *}$ & $16.6 \mathrm{~mm}^{* * *}$ & $15.4 \mathrm{~mm}^{* * *}$ & $20.2 \mathrm{~mm}^{* * *}$ & $5.2 \mathrm{~mm}^{* *}$ \\
\hline
\end{tabular}

* Neocaridina denticulata denticulata in original paper.

** Carapace length.

*** Body length.

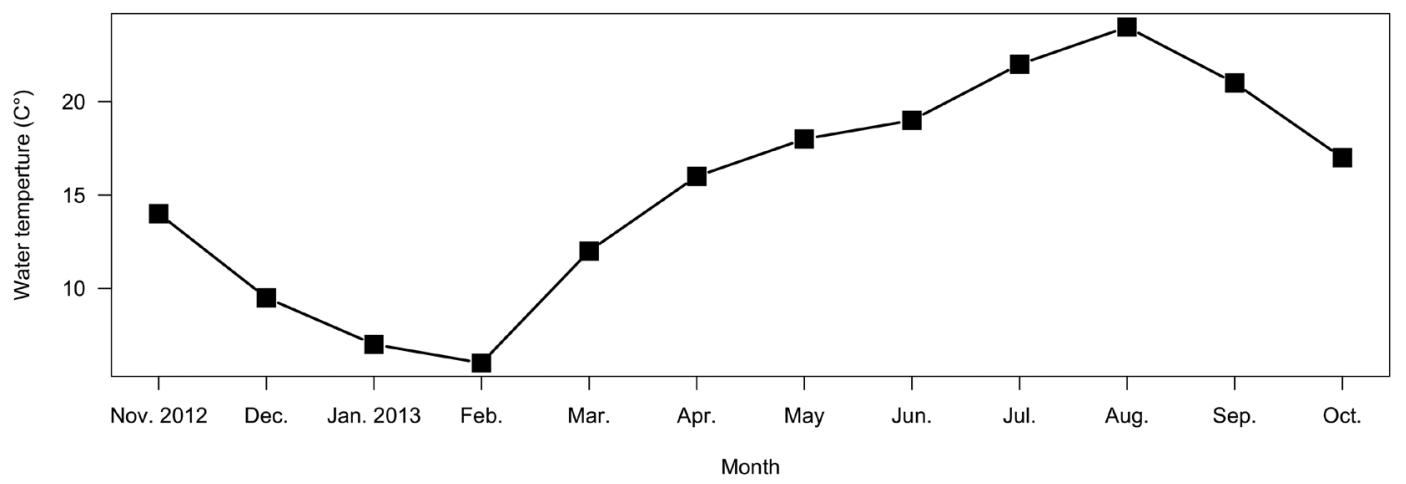

Fig. 2. Seasonal change in water temperature at Site 3 .

vember 2012, a small number of juveniles with carapace length greater than $2.0 \mathrm{~mm}$ were captured. Assuming that the same reproductive process occurred in 2013, juveniles collected in November 2012 are considered to be born 2012. Juveniles with a carapace length equal to or less than $2.0 \mathrm{~mm}$ were not collected from November 2012 to June 2013 because recruitment didn't occurred this period. From April 2013, ovigerous females appeared. From July to September 2013, juveniles with a carapace length equal to or less than $2.0 \mathrm{~mm}$ were abundant. Juveniles collected between July and October 2013 were considered to be born 2013. In
October 2013, many individuals were mature, a small number of juveniles with carapace length greater than $2.0 \mathrm{~mm}$ were captured.

Ovigerous females were collected during the period between April and September in 2013. Carapace length of the ovigerous females ranged from 5.0 to $7.7 \mathrm{~mm}$. From April to July 2013 , ovigerous females with a carapace length equal to or more than $6.0 \mathrm{~mm}$ were collected. Females of this size were collected from November 2012. These females were likely born in 2012, because females born from April to June in 2013 grew to carapace length 5.5$6.5 \mathrm{~mm}$ in October 2013. From August to Sep- 

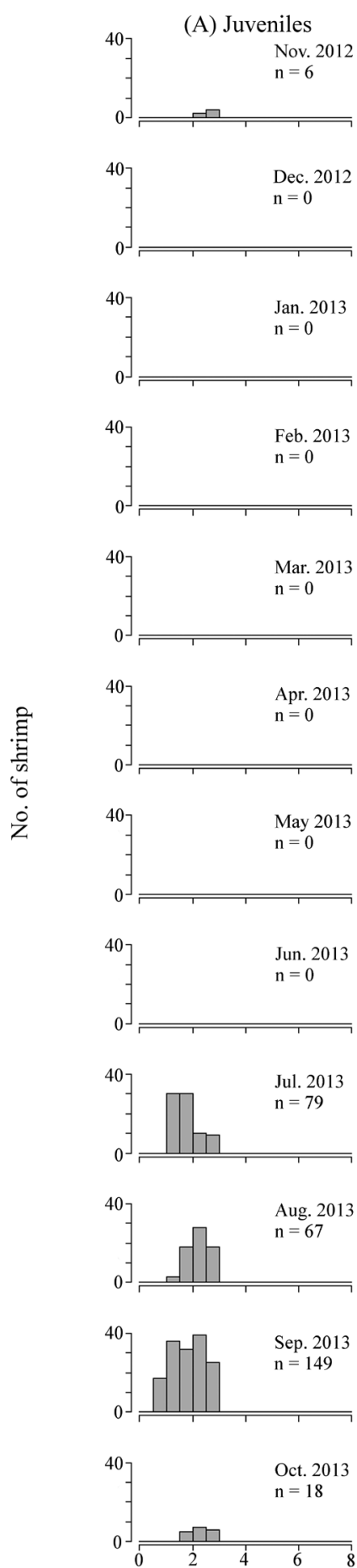

(B) Males

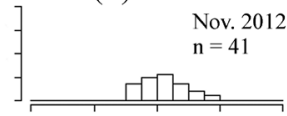

Dec. 2012

$\mathbf{n}=1$
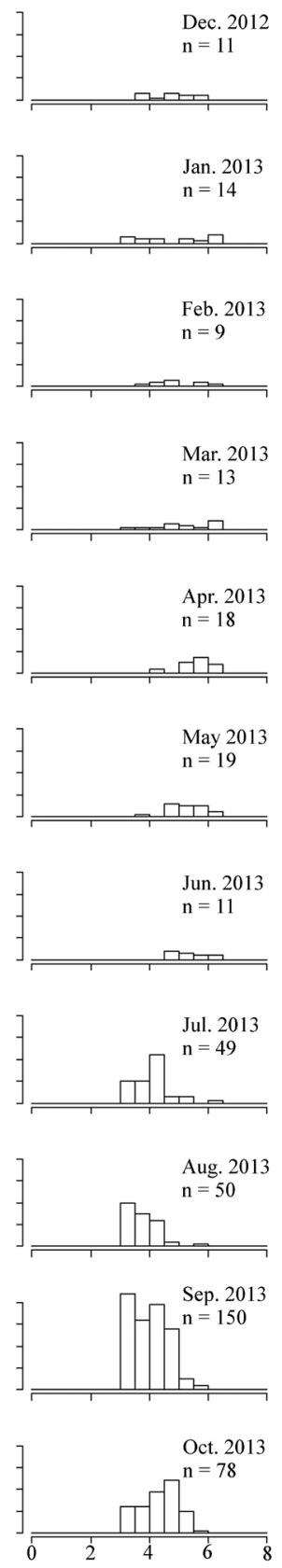

Carapace length $(\mathrm{mm})$
(C) Females
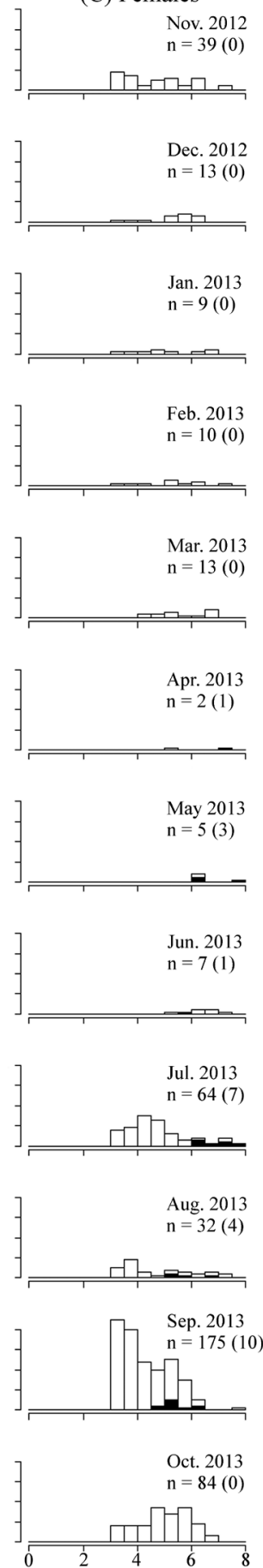

Cct. 2013 
tember 2013, ovigerous females with a carapace length equal to or less than $6.0 \mathrm{~mm}$ were collected. Females of this size were hardly collected from April to June 2013, but again collected in July 2013. Therefore, these females were likely born in 2013 .

The growth rate could not be quantified since the number of collected specimens from December 2012 to June 2013 was small. From July to August 2013, large males with a carapace length more than $6.0 \mathrm{~mm}$ were rarely collected or absent from collection. From September to October 2013, large females with a carapace length more than $7.0 \mathrm{~mm}$ were rarely collected or absent from collection.

The above-mentioned analysis of the sizefrequency histograms suggests that the life span of males is approximately 10 to 13 months and that of females is approximately 12 to 15 months. However, the sample size of shrimp from December 2012 to June 2013 was very small. More samples are needed to accurately estimate life span in this species. In particular, it is difficult to estimate whether large shrimp survive after the second year. However, the maximum size of specimens in the present study was almost the same as the maximum size of the specimens in previous studies (Ogawa et al., 1987; Niwa and Hamano, 1990; Sato et al., 1994). Therefore, we suggest that many of the specimens in the surveyed population reach their end of life in 10-15 months.

\section{Discussion}

The life history of $N$. davidi in the present study demonstrates that recruitment occurred from July to September, with the spawning period from April to September. From July to August, large males with a carapace length more than $6.0 \mathrm{~mm}$ were rarely collected or absent from collection. From September to October, large females with a carapace length more than $7.0 \mathrm{~mm}$ were rarely collected or absent from collection. It was suggested that many of shrimp reached the end of life in 10-15 months.

Comparisons between the life history of $N$. davidi in the Tomoe River and that of $N$. denticulata as reported in previous studies (Ogawa et al., 1987; Niwa and Hamano, 1990; Sato et al., 1994; Oh et al., 2003) are presented in Table 1. Overall, the life history of $N$. davidi in the present study is quite similar to that of $N$. denticulata reported in previous studies. For example, the recruitment period was from June to September, the spawning season was from April to September, the period that large shrimps were rarely collected or absent from collection was from June to October, the life span is $10-15$ months, and the maximum body length is $25.3 \pm 1.19 \mathrm{~mm}$ in males and $29.4 \pm$ $0.59 \mathrm{~mm}$ in females.

Niwa and Hamano (1990) reported the occurrence of a short generation group in the population of $N$. denticulata in the Sugow River, Hyogo Prefecture. The short generation group was recruited in early June, grew rapidly, spawned, and disappeared in August. In the present study, ovigerous females with a carapace length equal to or less than $6.0 \mathrm{~mm}$ were collected from August to September. These shrimp may belong to a short generation group. However, there is an additional possibility. These shrimp may belong to a long generation group. Ogawa et al. (1987) and Niwa \& Hamano (1990) pointed out the possibility that some shrimp in the long generation group that grow rapidly may breed twice, with the first reproductive season in the recruiting year and the second reproductive season in the following year. To clarify this issue, the sampling of shrimp should be done over shorter intervals in summer to more precisely assess population fluctuation.

Both Neocaridina denticulata and N. davidi inhabited rivers mid-stream, lakes, marshes, and irrigation canals where emergent plants were abundant (Kamita, 1970; Ogawa et al., 1987; Sato et al., 1994; Suzuki \& Sato, 1994; 
Englund \& Cai, 1999; Oh et al., 2003; Liang, 2004; Hayashi, 2007; Suzuki \& Naruse, 2011; Toyota \& Seki, 2014). This sympatry potentially leads to competition between the two species for habitat.

Nishino (2009) suggested the possibility of interspecific hybridization between $N$. denticulata and Neocaridina spp., including $N$. davidi (as $N$. heteropoda), since, in the surveyed area, these species were co-inhabited out of the same local habitat. However, it should be noted that interspecific hybridization between the two species has not yet been demonstrated in breeding experiments. If interspecific hybridization between $N$. davidi and $N$. denticulata is biologically possible, there is a risk of interbreeding in the natural environment, since their life cycles and habitats well overlap with each other, potentially leading to strong competition between them.

\section{Acknowledgements}

We thank the late Dr. Y. Usami (Tokyo University of Marine Science and Technology) for useful discussion on the subject. We wish to thank Professor Stephen G. Dunbar (Loma Linda University, USA) for English editing and content review. We are also grateful to the two anonymous reviewers for their valuable comments on this manuscript.

\section{Literature Cited}

Cai, Y., 1996. A revision of the genus Neocaridina (Crustacea: Decapoda: Atyidae). Acta Zootaxonomica Sinica, 21(2): 129-160. [In Chinese with English abstract]

Englund, R. A., \& Cai, Y., 1999. The occurrence and description of Neocaridina denticulata sinensis (Kemp, 1918) (Crustacea: Decapoda: Atydae), a new introduction to the Hawaiian Islands. Bishop Museum Occasional Papers, 58: 58-65.

Fujita, J., Nakayama, K., Kai, Y., Ueno, M., \&
Yamashita, Y., 2011. Comparison of genetic population structures between the landlocked shrimp, Neocaridina denticulata denticulata, and the amphidromous shrimp, Caridina leucosticta (Decapoda, Atyidae) as inferred from mitochondrial DNA sequences. New Frontiers in Crustacean Biology: 183-196.

Hamano, T., Kamada, M., \& Tanabe, T., 2000. Distributions of freshwater decapod crustacean in Tokushima Prefecture, Japan, with notes on conservation methods for local populations. Bulletin of the Tokushima Prefectural Museum, 10: 1-47. [In Japanese with English abstract]

Hayashi, K., 2007. Prawns, shrimps and lobsters from Japan II-Caridea I. Seibutsu Kenkyusha, Tokyo, 306 pp. [In Japanese]

Kamita, T., 1970. Studies on the fresh-water shrimps, prawns and crawfishes of Japan (Revised and enlarged edition). Sonoyama Syoten, Matsue, 213 pp. [In Japanese with English abstract]

Klotz, W., Miesen, F. W., Hullen, S., \& Herder, F., 2013. Two Asian fresh water shrimp species found in a thermally polluted stream system in North Rhine-Westphalia, Germany. Aquatic Invasions, 8(3): 333-339.

Kubo, I., 1938. On the Japanese atyid shrimps. Journal of the Imperial Fisheries Institute, Tokyo, 33: 67-100.

Liang, X. Q., 2004. Fauna Sinica. Invertebrata. Vol. 36. Crustacea. Decapoda. Atyidae. Science Press, Beijing, China, 375pp. [In Chinese with English abstract]

Mitsugi, M., Hisamoto, Y., \& Suzuki, H., 2017. An invasive freshwater shrimp of the genus Neocaridina Kubo, 1938 (Decapoda: Caridea: Atyidae), collected from Boso Peninsula, Tateyama City, Chiba Prefecture, eastern Japan. Crustacean Research, 46: 83-94.

Nishino, M., 2009. Genetic pollution and disturbance of symbiotic system of the freshwater shrimp, Neocaridina denticulata denticulata, by the invasion of closely related alien species. Report of the Grant-in-Aid for Scientif- 
ic Research (no.60237716) by Ministry of Education, Science, Sports and Culture. 4 pp. [In Japanese with English abstract]

Niwa, N., \& Hamano, T., 1990. Population ecology of Neocaridina denticulata (De Haan, 1849) (Caridea, Decapoda) in the Sugow River, Japan. Researches on Crustacea, 19: 43-54. [In Japanese with English abstract]

Niwa, N., 2010. Invasion and dispersion routes of alien alive freshwater shrimps Neocaridina spp. (Caridea, Atydae) and Palaemonidae spp. (Caridea), imported into Japan. Cancer, 19: 75-80. [In Japanese]

Ogawa, Y., Kakuda, S., \& Wakashita, F., 1987. On the ecology of Neocaridina denticulata (Decapoda, Atydae) inhabiting the Ashida River, eastern region of the Hiroshima Prefecture. Aquaculture Science, 35(1): 33-41. [In Japanese with English abstract]

Oh, C., Ma, C., Hartnoll, R. G., \& Suh, H., 2003. Reproduction and population dynamics of the temperate freshwater shrimp, Neocaridina denticulata denticulata (De Haan, 1844), in a Korean Stream. Crustaceana, 76(8): 993-1015.

R Development Core Team, 2016. R: A language and environment for statistical computing. $\mathrm{R}$ Foundation for Statistical Computing. (URL: http://www.R-project.org.)

Sato, M., Arai, K., \& Ohara, Y., 1994. Distribution of freshwater shrimps, a prawn and a crayfish, and life history of Neocaridina denticulata denticulata in the system of Ma- nose Rivers in Kagoshima Prefecture, southern Japan. Report of the Faculty of Science, Kagoshima University, Earth Sciences and Biology. 27: 245-262. [In Japanese with English abstract]

Suzuki, H., \& Sato, M., 1994. Kagoshima Nature Guide, Freshwater Shrimps, Crayfish, and Crabs. Nishinihon Shinbunsha, Fukuoka, 137 pp. [In Japanese]

Suzuki, H., \& Naruse, T., 2011. Freshwater decapod crustaceans of Japan. In: Kawai, T. \& Nakata, K., (eds.), Conservation Biology of Freshwater Crustaceans. Seibutsu Kenkyusha, Tokyo, pp. 39-73, 121-122. [In Japanese]

Toyota, K., \& Seki, S., 2014. Freshwater Shrimp and Crab in Japan. Seibundo Shinkosha, Tokyo, Japan, 255 pp. [In Japanese]

\section{Addresses}

(MM) The University of Tokyo Chiba Forest, 770 Amatsu, Kamogawa, Chiba 299-5503, Japan

(HS) The United Graduate School of Agricultural Sciences Kagoshima University, 1-21-24 Korimoto, Kagoshima 890-0065, Japan

\section{E-mail Address of corresponding author}

(MM)shiodamari98@gmail.com 